\title{
Samsun İli Batı Parkı’nın Peyzaj Özelliklerinin Değerlendirilmesi
}

\section{Alihan KINDAN ${ }^{1}$ (D), Nuray ÇIÇEK ${ }^{*}$ (D) \\ ${ }^{1}$ Çankırı Karatekin Üniversitesi Orman Fakültesi Peyzaj Mimarlığı Bölümü, Çankırı}

Öz: Kent parkları, kentsel açık yeşil alan sisteminin önemli bir öğesidir. Kent insanı için sağladığı aktif ve pasif kullanımların yanı sıra kent estetiğine ve kentin yeşil kimliğine önemli katkılar sağlar. Çalışma alanı olarak seçilen Batı Park, Samsun ilinde bulunan bir kent parkıdır ve ilk defa bu araştırma ile peyzaj özellikleri değerlendirilmiştir. Çalışmada öncelikle Batı Park da bulunan 41 ağaç türü, 8 ağaçcık türü, 19 çalı türü ve 3 yer örtücü ve sarılıcı tür teşhis edilerek listelenmiştir. Daha sonrasında çalışma alanının öne çıkan olumlu ve olumsuz özelliklerini belirlemek için Batı Park farklı zamanlarda altı defa ziyaret edilerek gözlemlenmiş ve gerekli notlar alınarak değerlendirilmiştir. Yapılan değerlendirmede çalışma alanının bitki çeşitliği, konumu, ulaşım kolaylığı, mevcut otopark, parkın etrafındaki diğer yapılar, sunduğu farklı aktif ve pasif faaliyetler, çevre düzenlemesi ve döşemeler olumlu özellikler olarak tespit edilmiştir. Diğer taraftan bazı alanlar için yanlış bitki seçimi, bakımsız koşu yolu ve çocuk oyun alanları, mesire alanı ve bazı peyzaj donatı elemanlarının yetersizliği ve bakımsızlı̆ı olumsuz özellikler arasında yer almıştır. Araştırmada Batı Park'ın farklı gelir düzeyine ve her yaş grubuna hitap edilebilecek bölge için önemli bir kent park olduğu sonucuna varılmıştır. Çalışmanın sonucunda Batı Park'ın Samsun kentinin yeşil kimliğine sürdürülebilir katkılar yapacak öneriler sunulmuştur.

Anahtar Kelimeler: Batı Park, bitki çeşitliği, kent park, donatı elemanı

\section{Assessing the Landscape Characterictics of Batı Park in Samsun City-Turkey}

Abstract: City parks are important urban members of open green space system. They provide active and passive uses for urban people and also contribute to the green identity and esthetics of the city. Batı park, chosen as the study area, was a city park in Samsun city and initially assessed its landscape characteristics by means of this research. At this study, we primarily identified and listed 41 tree, 8 shrub, 19 bush and 3 ground covers and clutching stem species in Batı Park. Afterwards, to specify the prominent positive and negative characteristics of the study area, necessary notes were taken and finally assessed them by visiting six times at different periods and observing it. According to the evaluation, the followings were determined as positive characteristics: Plant variety of the study area, the location, easiness of transportation, the existing parking area, other structures around the park, different active and passive activities offered and landscaping and flooring. On the other hand, the followings were the negative characteristics: Inaccuracy of the tree choice, uncared running path and playgrounds, picnic area and poorness and dilapidation of some landscape fittings members. At this study, we concluded that Batı Park, was an important city park for the region, addressing to the all age groups and to different level of incomes. Finally, Batı Park would attribute to Samsun city to its sustainable green identity.

Keywords: Batı Park, plant variety, city park, outdoor furniture

\section{GiRiş}

Dünya nüfusundaki artış, kentlerin de hızlı büyümesine sebep olmuştur. Bu büyüme çoğunlukla plansız, estetikten uzak ve çarpık gerçekleşmiştir. Bu bağlamda büyük kentlerde açık yeşil alanlar giderek azalmıştır. Artan beton ve çok katlı yapılar, azalan yeşil alanlar ve doğadan uzaklaşma zaman ile insanlarda psikolojik sorunlara ve fiziksel olumsuzluklara sebep olmaktadır.

Yoğun kent karmaşası içerisinde bulunan, hayat baskısı altındaki kent insanlarının psikolojik rahatlamaya ihtiyaç duyması, fiziksel ve ruhsal gelişimini sağlayıcı (rekreasyonel) faaliyetlerde bulunması ve bireyler ile bir arada bulunarak sosyo-kültürel gelişiminde açık ve yeşil alanlar etkilidir (Etli, 2002). Kent parkları, açık yeşil alan sisteminde bu hizmetleri gerçekleştirebilecek kentsel kamusal dış mekan ünitelerinden birisidir. Kent parkları kentlerin rahatlatıcı, huzur verici, fonksiyonel ve estetik alanlarıdır. Bu nedenle, bulundukları kentlerin en seçkin yerlerinde doğal güzellikleri ve özellikleri açısından her yaş grubu için her türlü aktif ve pasif rekreasyon olanaklarına ve tesislerine sahip olacak şekilde planlanması önemlidir (Boyacı, 2010). Bu bağlamda kent parkları korumaya, kullanmaya, sağlığa ve eğitime olanak sağlarken, toplumsal yaşamda da etkin bir rol oynar (Polat, 2001). İngiltere'de Mori Sosyal Araştırma Enstitüsü'nün yaşam kalitesi üzerine 2001 yılında yaptığı bir araştırmada, her beş kişiden birinin, parklar ve açık alanları en önemli kamu hizmeti olarak gördüklerini belirtmişlerdir. Araştırmanın devamında parkların daha yaşanabilir ortamlar için kullanıcılara sosyal fayda, sağlık faydaları, eğitici faydalar, çevresel faydalar ve ekonomik faydalar sunduğu açıklanmıştır (Duffy, 2003).

Kent parkları; kullanıcılarına kentin yoğun ve stresli atmosferinden uzaklaşarak bir çok pasif ve aktif rekreasyon olanaklarının sunulduğu, her yaş grubuna hitap eden, yürüme mesafesi olarak ortalama 30 ila 60 dakikalık ve

*Sorumlu Yazar: ciceknuray@karatekin.edu.tr. Bu çalışma lisans tez ürünüdür.

Geliş Tarihi: 31 Aralık 2019

Kabul Tarihi: 3 Aralık 2020 
kentlere olan uzaklığı yaklaşık 2 ila $4 \mathrm{~km}$ mesafesinde olup toplu taşım araçları ile ulaşımı mümkün olan, yürüyüş ve koşu yolları, gölet veya spor alanları, piknik alanları, spor kompleksleri, amfi tiyatro, seyir kulesi, restoran, oturma elemanları, çocuk oyun grupları bulunan ve kullanıcıların tek başına yada grup olarak etkinlikler düzenlenmesine fırsat tanıyan, bitki materyalleri ile bir bütünlük içerisinde olan, eğitici, kazandırıcı özellikler taşıyan, planlı olarak tasarlanmış yeşil alanlardır (Özdemir, 2012). Diğer taraftan kent parkları kentin ekolojik dengesini koruyan kent içi açık yeşil alanlardır (Ertekin, 1992; Özkır, 2007).

Kent parklardan en üst düzeyde faydalanma öncelikli olarak konum, büyüklük, ulaşılabilirlik, yeşil alanın niteliği ve sunu çeşitliliği gibi konularda yeterliliği ve kent halkına uygun kullanım koşulları oluşturmasıyla sağlanacaktır. Bunun için kentsel alanlarda yeşil alanların planlaması, tasarımı, uygulaması ve bakımının yeterince yapılması gereklidir. Öncelikle bu aşamaların hepsinde uzman ve yetkili kişilerin olması, özellikle peyzaj mimarlarının yeşil alan oluşturma çalışmalarının her aşmasında görev alması gereklidir (Önder ve Polat, 2012).

Çeşitli araştırıcılar tarafından, kent park ve açık yeşil alanların, kent kimliği için önemi, peyzaj ve estetik özelliklerini değerlendirme yöntemleri, yönetim modelleri, kullanıcı tercihleri, kent parklarının yaşam kalitesi üzerine etkileri, donatı elemanları ve mekanın sürekliğini korumak için gerekli aktiviteler değerlendirilmiştir (Yücel, 2006; Yücel ve Yıldızcı, 2006; Topaloğlu, 2007; Onsekiz ve Emür, 2008; Gül ve Küçük, 2009; Boyacı, 2010; Polat, 2012; Bilgili, 2013; Bekçi ve Taşkan, 2014; Aykan ve ark., 2017; Kaya ve ark., 2018; Önal ve Sağır, 2018; Yücedağ ve ark., 2018; Kaya ve ark., 2019).

Bu çalışmada, Samsun ilinde bulunan Batı Park'ın bitki çeşitliliği tespit edilerek listelenmiştir. Batı Park farklı zamanlarda altı defa ziyaret edilerek gözlemlenmiş özellikle bitki ve parkın genel bakımı konusunda notlar alınarak değerlendirilmiştir. Araştırmanın sonucunda çalışma alanının bazı peyzaj özellikleri, bitki çeşitliliği, park bakımı ve donatı elemanlarının özellikleri ortaya konmuş ve öneriler sunulmuştur.

\section{MATERYAL VE YÖNTEM}

\section{Materyal}

Çalışma alanı olan seçilen Batı Park Türkiye'nin kuzeyinde Doğu Karadeniz bölgesinde bulunan Samsun iline ait bir kent parktır (Şekil 1). Yaklaşık 82 ha bir alana sahip olan Batı Park (4119'18.7"N 36²19'28.8"E) kıyı şeridinde bulunması nedeni ile çalışma alanında tipik Akdeniz iklimi mevcuttur. Samsun iline ait yaşlara göre nüfus dağılımı Çizelge 1 de gösterilmiştir (TUIK, 2018).

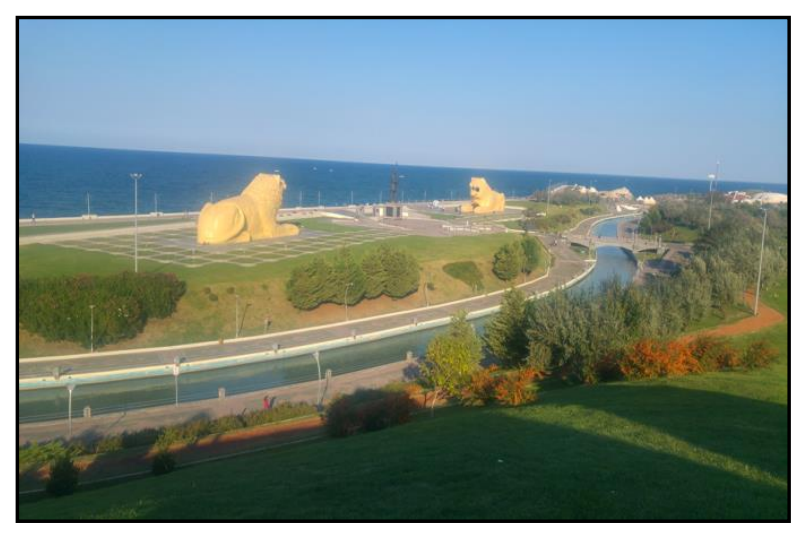

Şekil 1. Batı Park Amozon Heykeli ve Aslanlar (Orijinal)

Çizelge 1. Samsun ilinin yaşlara göre nüfus dağılımı

\begin{tabular}{lcc}
\hline Yaş Aralığı & Nüfus & Oran (\%) \\
\hline $0-14$ & 273.641 & 20.49 \\
$15-64$ & 913.109 & 68.36 \\
$65+$ & 148.966 & 11.15 \\
Toplam & 1.335 .716 & 100 \\
\hline
\end{tabular}

\section{Yöntem}

Bu araştırma 2018-2019 yılları arasında gerçekleştirilmiştir. Araştırma metodu olarak yerinde gözlem, inceleme, analiz ve değerlendirme aşamaları kullanılmıştır. Bu bağlamda Batı Park 6 defa farklı dönemlerde incelenmiştir (şubat 2018, mayıs 2018, temmuz 2018, ekim 2018, şubat 2019, mayıs 2019).

Çalışma alanında ki bitkiler yerinde gözlem, ÇAKÜ Orman Fakültesi Peyzaj Mimarlığı Bölümü'nde (2018-2019 öğretim yılı Proje III ve Proje IV dersleri kapsamında) ve çeşitli kaynaklardan (Davis, 1965-1985; Combes, 1992; Brickell, 1996; Dirr, 1998) faydalanılarak teşhis edilmiştir.

\section{BULGULAR VE TARTIŞMA}

Çalışma alanı olan Batı Park'ta bitki çeşitleri tespit edilerek; ağaç türleri, ağaççık ve çalı türleri ve yer örtücü/sarılıcı türler olarak dört farklı grupta sınıflandırılmıştır (Çizelge 2, Çizelge 3 ve Çizelge 4). Çizelgelerin incelenmesinde anlaşılacağı gibi park alanında 41 ağaç türü, 8 ağaçcık türü, 19 çalı türü ve 3 yer örtücü ve sarılıcı tür bulunmaktadır. Bu bağlamda Batı Park bitki çeşitliliği, uyumu ve sayısı bakımından kentin yeşil kimliğine katkı yapan zengin bir mekandır (Şekil 2). Bu çeşitlilik verileri peyzaj açısından Batı Park'ın en güçlü ve olumlu özelliğidir.

Samsun ili nüfus dağılım çizelgesi (Çizelge 1) göz önüne alındığında, genç ve orta yaşa ait nüfus oranının fazla olduğu görülmektedir. Bu bağlamda bu durumun alanın kullanımına etkisinin olumlu olduğu ve kent parkta bulunan orta yaş ve özellikle gençlere yönelik faaliyetlerin yoğun olarak kullanıldığı gözlemlenmiştir. Örneğin alanda mevcut 
Çizelge 2. Batı Park'ta bulunan ağaç türlerinin Latince ve Türkçe isimleri

\begin{tabular}{|c|c|}
\hline Acer negundo & Dişbudak yapraklı akçağaç \\
\hline Acer platonoides & Çınar yapraklı akçağaç \\
\hline Acer pseudoplatanus & Dağ akçaağacı \\
\hline Aesculus hippocastanum & At kestanesi \\
\hline Betula pendula & Adi huş \\
\hline Catalpa bignoniodies & Katalpa \\
\hline Cercis siliquastrum & Erguvan \\
\hline $\begin{array}{l}\text { Chamaecyparis lawsoiana cv. } \\
\text { 'Ellwoodii' }\end{array}$ & Laswon yalancı servisi \\
\hline Cupressocyparis leylandii & Leylandi servisi \\
\hline Cupressus arizonica & Arizona servisi \\
\hline Cupressus goweiana & Kokulu servisi \\
\hline Cupressus macrocarpa & Monteri servisi \\
\hline Cupressus sempervirens & Akdeniz servisi \\
\hline Elaeagnus angustifolia & Kuş iğdesi \\
\hline Elaeagnus multiflorum & Kırmızı iğde \\
\hline Elaeagnus pungens & İğde \\
\hline Ficus carica & İncir \\
\hline Fraxinus exelsior & Yaygın dişbudak \\
\hline Juglans regia & Ceviz \\
\hline Lagerstromeria indica & Oya ağacı \\
\hline Magnolia grandiflora & Manolya \\
\hline Melia azaderach & Tesbih ağacı \\
\hline Nerium oleander & Zakkum \\
\hline Paulownia tomentosa & Tüylü pavlonya \\
\hline Phoneix dectilifera & Palmiye (hurma) \\
\hline Picea abies & Avrupa ladini \\
\hline Pinus brutia & Kızılçam \\
\hline Pinus nigra & Karaçam \\
\hline Pinus pinea & Fıstık çamı \\
\hline Platanus acerifolia & Londra çınarı \\
\hline Platanus orientalis & Doğu çınarı \\
\hline Populus alba & Ak kavak \\
\hline Prunus avium & Kiraz \\
\hline Prunus ceracifera & Süs eriği \\
\hline
\end{tabular}

Çizelge 2. Batı Park'ta bulunan ağaç türlerinin Latince ve Türkçe isimleri (Devam)

\begin{tabular}{ll}
\hline Quercus robur & Saplı meşe \\
Robinia pseudoacacia & Yalancı akasya \\
Salix alba & Ak söğüt \\
Salix babylonica & Salkım söğüt \\
Sophora japonica & Sofora \\
Tamarix tetrendra & Ilgın \\
Trachycarpus fortunei & Telli palmiye
\end{tabular}

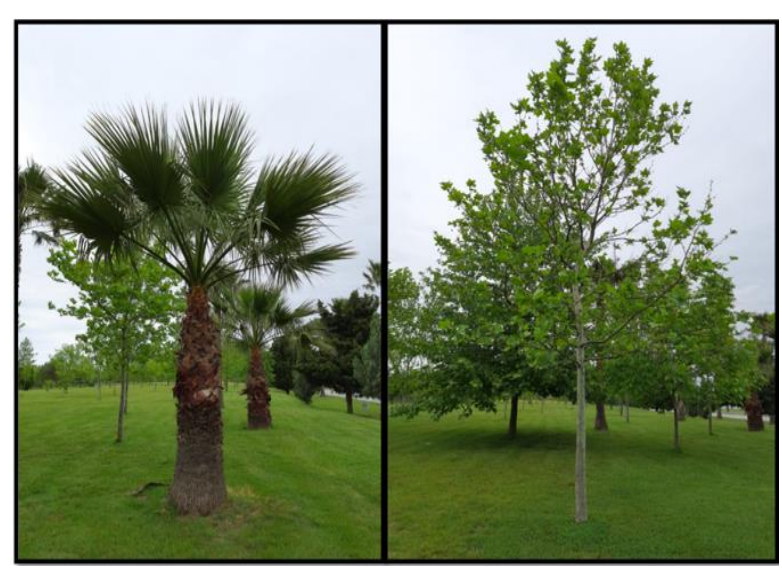

Şekil 2. Batı Park'ın bitki çeşitliliği (Orijinal)

olan go-kart, basketbol, futbol, tenis, atçılık-binicilik, yamaç paraşütü, macera parkı, gondol, kano, dragon, deniz bisikleti gibi aktiviteler gençler tarafından tercih edilmektedir. Batı Park'ın yakınlarında Ondokuz Mayıs Üniversitesi, Güzel Sanatlar Fakültesi'nin bulunması, parkı üniversite öğrencilerinin uğrak noktası haline getirmiştir. Diğer taraftan 65 yaş ve üstü kullanıcılar için mesire alanı, seyir terası, çay bahçesi, sahil kenarı oturma elemanları gibi alanlar mevcuttur. Parkların en önemli kullanıcı gruplarından olan 0 ile 14 yaş aralığı için çocuk oyun alanları, çizgi film karakterlerinden oluşan maket alanı ve Amazon Adası bulunmaktadır. Ziyaretçilerine birçok farklı olanak sağlayan Batı Park'ın çok sayıda ücretsiz kullanım alanına sahip olması kullanıcı sayısını arttırmaktadır. Bu bakımdan Batı Park farklı ekonomik statülere sahip en küçük kullanıcıdan en yaşlı kullanıcıya kadar her kesime hitap etmektedir. Bu durum yine Batı Park'ın güçlü ve olumlu özelliklerinden biridir.

Karadeniz Sahil şeridinde bulunması nedeniyle Batı Park açık bir trafiğin yanında konumlanmıştır. Bu durum araç sahibi kullanıcılara kolaylık sunmakta ve yanından geçmekte olan tramvay ile büyük bir kitlenin rahat bir şekilde alana ulaşmasını sağlamaktadır. Bununla beraber dolmuş duraklarının yakın olması bir diğer ulaşım kolaylığıdır. Bu bağlamda çeşitli vasıtalar ile alana sorunsuzca 
Çizelge 3. Batı Park'ta bulunan ağaççık ve çalı türlerinin Latince ve Türkçe isimleri

\begin{tabular}{|c|c|}
\hline Abelia $\times$ grandiflora & Büyük çiçekli kelebek çalısı \\
\hline Agave americana & Sabır tuzluğu \\
\hline Berberis thunbergii & Kadın tuzluğu \\
\hline Callistemon viminalis & Fırça çalısı \\
\hline Cornus alba & Kızılcık \\
\hline Cycas revoluta & Yalancı suga palmiyesi \\
\hline Euonymus japonica & Taflan \\
\hline Ficus elastica & Kauçuk \\
\hline Hibiscus syriacus & Hatmi \\
\hline Juniperus chinensis & Çin ardıcı \\
\hline Juniperus sabina & Sabin ardıcı \\
\hline Kouelroiteria paniculata & Güvey kandili \\
\hline Laurus nobilis & Akdeniz defnesi \\
\hline Ligustrum japonica & Japon kurtbağrı \\
\hline Ligustrum lucidum & Japon kurtbağrı \\
\hline Photinia $x$ fraseri & Alev çalısı \\
\hline Pittosporum tobira & Yıldız çalısı \\
\hline Prunus laurocerasus & Karayemiş \\
\hline Prunus serrulata cv. 'Kanzan' & Japon süs kirazı \\
\hline Pyracantha coccinea & Ateş dikeni \\
\hline Rosa sp. & Gül \\
\hline Rubus sp. & Böğürtlen \\
\hline Symphoricarpos arbiculatus & İnci çalısı \\
\hline Syringa vulgaris & Leylak \\
\hline Thuja orientalis & Doğu mazısı \\
\hline Viburnum tinus & $\begin{array}{l}\text { Tüylü kartopu } \\
\text { yapraklı kartopu) }\end{array}$ \\
\hline Yucca flamentosa & Avize çiçeği \\
\hline
\end{tabular}

Çizelge 4. Batı Park'ta bulunan yer örtücü ve sarılıcı türlerinin Latince ve Türkçe isimleri

\begin{tabular}{ll}
\hline Hedera helix & Orman sarmaşığı \\
Lonicera caprifolium & Yabani hanımeli \\
Parthenocissus quinqefolia & Amerikan sarmaşığı \\
\hline
\end{tabular}

ulaşılabilmektedir. Ulaşım ile ilgili bir diğer önemli nokta olan otoparkların varlığı park ve açık yeşil alanlara kendi araçları ile ulaşmak isteyen kullanıcılar için bir düzen oluşturmaktadır. Batı Park içerisinde üç noktada bulunan toplam 350 araç için çizilmiş ve çizilmemiş sert zemin üzerine kullanıcıların park yaptıkları gözlemlenmiştir. Diğer taraftan Park'ın merkezinden Amisos Tepe'sine ulaşımı sağlamak için bir teleferik düzeneği kurulmuştur. Teleferik, park içi kullanımı artırmak ile birlikte Amisos tepesiyle Batı Park arasında bağ kurarak kullanıcıların Amisos Tepesinde bulunan tarihi yapıları ziyaret etmesini sağlamaktadır. Ulaşım kolaylığı ve otoparkların varlığı alanın kullanılabilirliğini arttıran olumlu ve güçlü yönlerinden birini oluşturmaktadır. Nitekim, Yücedağ ve ark. (2018) DenizliPamukkale'deki kent parklarının ve Kaya ve ark. (2019) Antalya-Dokuma parkı'nın kente yürüme mesafesinde olmalarından dolayı kullanıcıların parkları büyük ölçüde yürüyerek ziyaret ettiklerini belirtmişlerdir.

Alan içi kullanımlar değerlendirildiğinde öncelikle Batı Park'ın sahil şeridinde bulunması ve sahil şeridi boyunca Karadeniz'i gören oturma alanları varlığı kullanıcılara güzel ve huzur verici bir ortam sağlamaktadır. Ziyaretçilerine deniz kenarında kullanım olanakları sağlanması Batı Park'ın ilgi çekici ve güçlü yönlerinden birini oluşturmaktadır. Her yaş kesiminin kullanabileceği fakat daha çok 65 yaş ve üstü nüfusun kullandığı gözlemlenen bu alanda sahil şeridi boyunca oturma alanı dışında yürüyüş, koşu ve bisiklet yolları da mevcuttur. Bu anlamda, Kaya ve ark. (2019) yeni parkların tesis sürecinde ziyaretçilerin demografik özelliklerinin göz ardı edilmemesi gerektiğini vurgulamışlardır.

Park alanında kullanıcıları bilgilendirici, yönlendirici ve bilgilendirici levhaların bulunması önemli bir husustur. Batı Park'ı içerisinde de yeterli miktarda bilgilendirici, yönlendirici ve uyarıcı levhaların bulunduğu gözlemlenmiştir. Bunlar; Yamaç paraşüt çalışma alanı, bisiklet yolu, çocuk oyun parkı kullanım kuralları, uluslararası işaret sancakları ve anlamları, balık tutmak yasaktır, atçılık-binicilik alanı kuralları, kanala yaklaşmak tehlikelidir ve alanlara yönlendirici levhalardır. Bu levhaların varlığı alan içi faaliyetlerin kolaylığını sağlamakta olup kullanıcıya yön göstermektedir. Bu durum Batı Park'ın güçlü ve olumlu yönlerini destekleyici bir unsurdur.

Batı Park'ta bir kaç küçük olumsuzluk dışında (çimlere yama yapılması ve bazı donatı elemanlarının onarımı) genel anlamda güzel bir çevre düzenlemesi mevcuttur (Şekil 3). Diğer taraftan yürüyüş yollarının bozuk ve kötü görüntüye sahip noktalarında farklı türden ve renkten döşemelerin kullanılması kötü görüntülerin kapatmasına neden olmuştur. Park, kullanıcılarına iyi bir çevre düzenlemesi yanı sıra geniş bir alana sahip olması nedeni ile farklı park içi kullanım imkanı da sunmaktadır. Bu bağlamda çeşitli spor 


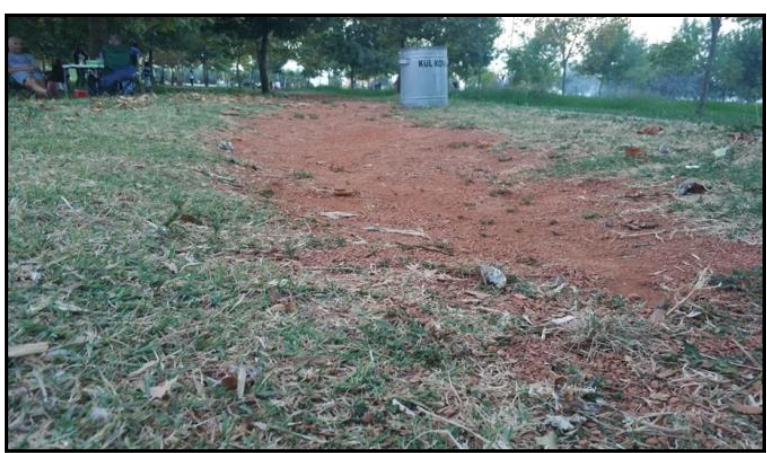

Şekil 3. Batı Park içinde seyrelmiş olan çim örtüsü (orijinal)

aktivitelerinin yanı sıra kullanıcılarına lokanta ve çay bahçesi gibi alternatifler sunmaktadır. Yücedağ ve ark. (2018) Denizli-Pamukkale ilçesinin kent parkında yürüttükleri çalışmada, kullanıcıların en çok parkta yürüyüş yaptıkları, ikinci olarak da parkta bulunan spor aletlerini kullandıkları sonuçlarına ulaşmışlardır.

Batı Park'ın çevresinde bulunan yapılardan biri olan kapalı spor salonu ulusal ve uluslararası birçok spor karşılaşmasına ev sahipliği yapmıştır. Konu ile ilgili örnek vermek gerekirse 23. Yaz İşitme Engelliler Olimpiyatlarının yapıldığı salondur (Deaflympics 2017, 18-30 Temmuz). Bu bağlamda yurt içinden ve yurt dışından spor karşılaşmaları için gelen sporcular ve misafirler için de görülmeye değer nitelikte bir kent parkı özelliği taşımaktadır. Bu durum park için yine olumlu güçlü özellikler arasına girmektedir.

Batı Park'ın az sayıda da olsa olumsuz ve zayıf birkaç yönü bulunmaktadır. Park içerisinde bulunan yeşil alanların fazla olması nedeni ile aksayan bakım kötü görüntü oluşturmaktadır. Çimlerin uzaması ve yabani otların artması, yer örtücülerin fazlasıyla yayılarak koşu yolları gibi alanlara taştığı gözlemlenmiştir. Diğer taraftan çocuk oyun alanında da kırık ve paslanma gibi çocuklara zarar verecek bazı olumsuzluklar tespit edilmiştir.

Batı Park'ın deniz kıyısında olması fazla rüzgâra maruz kalmasına neden olmaktadır. Alan içerisinde bazı kısımlarda kullanılan boysuz ağaçlar rüzgârı engellemekte yetersiz kalmaktadır. Bu neden ile boylu ağaçların bu kısımlarda kullanılması tercih edilmelidir.

Kullanıcıların mesire alanlarına yoğun ilgi gösterdiği bazı günlerde mesire alanın yetersiz ve bakımsız kaldığı gözlemlenmiştir. Örneğin mesire alanının yakınlarında ki çöp kovalarının yetersizliği ve izole edilmemesi sonucu çöplerin biriktiği ve hoş olmayan kokunun yayıldığı belirlenmiştir.

\section{SONUÇ}

Parklar kent içinde en çok kullanılan açık alanlardır. Samsun ili için önemi büyük olan Batı Park genel anlamda bölge insanı için birçok kullanım olanağı sunmaktadır. Bu bağlamda Batı Park bahsedilen faydaları büyük oranda karşılamaktadır.

Araştırıcılar tarafından, çalışma alanının peyzaj özellikleri bakımından genelde kullanıcıların ihtiyaçlarını karşıladığı ve güzel bir peyzaja sahip olduğu tespit edilmiştir. Fakat özellikle çim alanlarının bakımı konusunda bazı küçük aksaklıkların olduğu gözlemlenmiştir. Bu çalışma ile Batı Park ilk defa peyzaj özellikleri bakımından değerlendirilmiştir. $\mathrm{Bu}$ neden ile çalışma daha sonra gerçekleştirilecek kapsamlı araştırmalar için bir altlık oluşturma ve öncü olma niteliğindedir.

\section{TEŞEKKÜR}

Bitki teşhislerinde emek veren Prof. Dr. Nazan KUTER, Doç. Dr. Umut PEKIN TiMUR, Dr. Öğr. Üyesi Özgür Burhan TIMUR, Arş. Gör. Dr. Pelin ŞAHIN KÖRMEÇLi ve Arş. Gör. İbrahim AYTAŞ ile öğrencilerimize teşekkür ederiz.

\section{KAYNAKLAR}

Aykal F, Yılmaz A, Çelik, S (2017) Kent Parklarının Erişilebilirliği Üzerine Bir Araştırma: Van Dilek Doğan Kent Parkı Örneği. Mühendislik Bilimleri ve Tasarım Dergisi, 5: 29-40.

Bekci B, Taşkan G (2012) Yeşil Alanlardaki Kent Donatılarının Kişisel Mekan Uzaklığına Etkisi: Bartın Kenti Örneği. Bartın Orman Fakültesi Dergisi, 14(22): 61-71.

Bilgili BC (2013) Çankırı Kenti Kamusal Yeşil Alanlarının Yeterliliğinin Ulaşılabilirlik Yönünden Değerlendirilmesi. Tekirdağ Ziraat Fakültesi Dergisi, 10(2): 21-25.

Boyacı E (2010) Ülkemizde Kent Parkı İşlevlerini Belirleyen Etmenler. Yüksek Lisans Tezi, Ankara Üniversitesi, Ankara.

Brickell C (1996) Encyclopedia of Garden Plants. Dorling Kindersley Lim. London.

Combes AJ (1992) Trees. DK Publishing, Inc. New York.

Davis PH (1965-1985) Flora of Turkey and East Aegean Islands. Edinburgh University Press. Edinburgh.

Dirr MA (1998) Manuel of Woody Landscape Plants. Stipes Publishing L.L.C. Illinois.

Duffy B (2003) Quality of life, Mori Research, Landscape Design. Landscape the Journal of Landscape Design Institute, 305 (39): 37-40.

Ertekin N (1992) Yeşil Alan Olarak İzmir İçin Önemi Olan Kültürparkın Bitki Varlığının Saptanması, Korunması ve Geliştirilmesi Üzerine Araştırmalar. Yüksel Lisans Tezi, Ege Üniversitesi, İzmir.

Etli B (2002) Edirne İli Merkez İlçe Yeșil Alan Sisteminin Peyzaj Mimarlığı İlkeleri Yönünden İrdelenmesi.

Trakya Üniversitesi Bilimsel Araștırmalar Dergisi, 3(1): 47-59.

Gül A, Küçük V (2009). Kentsel Açık-Yeşil Alanlar ve Isparta Kenti Örneğinde İrdelenmesi. Turkish Journal of Forestry, 2(1): 27-48.

Kaya LG, Yücedağ C, Aşıkkutlu S, Şeker E (2018). Parklarda Kullanıcılar için Kent Mobilyalarının Önemi. European Conference on Science, Art and Culture (ECSAC), 1922 April 2018, p. 443-448, Antalya, Turkey.

Kaya LG, Yücedağ C, Aşıkkutlu S, Şeker E (2019). Antalya Kentinde Dokuma Parkı Elemanlarının Kullanıcılar Tarafından Değerlendirilmesi. 4th European Conference on Science, Art Culture, 18-21 April 2019, p. 43-50, Antalya, Turkey. 
Onsekiz D, Emür S (2008) Kent Parklarında Kullanıcı Tercihleri ve Değerlendirme Ölçütlerinin Belirlenmesi. Erciyes Üniversitesi Sosyal Bilimler Enstitüsü Dergisi, 1(24): 69-105.

Önal S, Sağır M (2018) Ankara Kent Parklarının Kullanımının Belirlenmesi. Ankara Araştırmaları Dergisi, 6(1):77-90.

Önder S, Polat AT (2012) Kentsel ve Açık Ve Yeşil Alanların Kent Yaşamındaki Yeri Ve Önemi. Kentsel Peyzaj Alanlarının Oluşumu ve Bakım Esasları Semineri, 19 Mayıs 2012, Konya, 97-116.

Özdemir B (2012) Kent Parklarının Kentsel Yaşam Kalitesine Katkıları. Yüksek Lisans Semineri, Selçuk Üniversitesi, Konya.

Özkır A (2007) Kent Parkları Yönetim Modelinin Geliştirilmesi. Doktora Tezi, Ankara

Polat A (2001) Kent Parkı Kavramı ve Konya Kenti İçin Bir Kent Parkı Örneği. Yüksek Lisans Tezi, Selçuk Üniversitesi, Konya.
Polat A (2012) Kent Parklarında Görsel Kalite ve Doğallık Derecesi Arasındaki İlişkilerin Belirlenmesi. Journal of the Institute of Science and Technology, 2(3): 85-92.

Topaloğlu S (2007). Ankara Harikalar Diyarı Kent Parkı'nın Tema Park Kavramı Kapsamında İrdelenmesi. Yüksek Lisans Tezi, Zonguldak Karaelmas Üniversitesi, Zonguldak.

TÜiK (2018). Adrese Dayalı Nüfus Kayıt Sistemi, Ankara.

Yücedağ C, Kaya LG, Aşıkkutlu S (2018). A Study on Usage of Urban Parks: Case of Pamukkale-Denizli, Turkey. The International Conference on Engineering and Natural Sciences (ICENS), 2-6 May 2018, p. 78-82, Kiev, Ukraine.

Yücel GF, Yıldızcı AC (2006) Kent Parkları İle illgili Kalite Kriterlerinin Oluşturulması. ITÜ Dergisi/a, Mimarlık, Planlama, Tasarım, 5(2): 220-230. 